IZA DP No. 6538

Retirement: Does Individual Unemployment Matter? Evidence from Danish Panel Data 1980-2009

Trine Filges

Mona Larsen

Peder J. Pedersen

May 2012 


\title{
Retirement: Does Individual Unemployment Matter? Evidence from Danish Panel Data 1980-2009
}

\author{
Trine Filges \\ Danish National Center for Social Research \\ Mona Larsen \\ Danish National Center for Social Research \\ Peder J. Pedersen \\ Aarhus University \\ and IZA
}

Discussion Paper No. 6538

May 2012

IZA

P.O. Box 7240

53072 Bonn

Germany

Phone: +49-228-3894-0

Fax: +49-228-3894-180

E-mail: iza@iza.org

\begin{abstract}
Any opinions expressed here are those of the author(s) and not those of IZA. Research published in this series may include views on policy, but the institute itself takes no institutional policy positions.

The Institute for the Study of Labor (IZA) in Bonn is a local and virtual international research center and a place of communication between science, politics and business. IZA is an independent nonprofit organization supported by Deutsche Post Foundation. The center is associated with the University of Bonn and offers a stimulating research environment through its international network, workshops and conferences, data service, project support, research visits and doctoral program. IZA engages in (i) original and internationally competitive research in all fields of labor economics, (ii) development of policy concepts, and (iii) dissemination of research results and concepts to the interested public.
\end{abstract}

IZA Discussion Papers often represent preliminary work and are circulated to encourage discussion. Citation of such a paper should account for its provisional character. A revised version may be available directly from the author. 


\section{ABSTRACT \\ Retirement: Does Individual Unemployment Matter? Evidence from Danish Panel Data 1980-2009*}

The paper studies the impact from variations in unemployment on retirement among older workers. We integrate unemployment variations with early retirement programs and other pathways out of the labor force. The paper describes retirement programs, policy changes, labor force participation among older workers and presents a new estimate of the trend in the average age of retirement. Individual panel data for the last 25 years are used in estimations of the impact from individual unemployment on the retirement decision. Unemployment is found highly significant and quantitatively important for the retirement decision. We conclude that there is a clear risk of a cyclical downturn resulting in a more long run reduction in productive capacity with negative consequences for the budget of the public sector.

JEL Classification: $\quad$ E32, J21, J26, J64

Keywords: unemployment, labor force participation, retirement

Corresponding author:

Peder J. Pedersen

Department of Economics and Business

Bartholins Alle 10

Aarhus University

8000 Aarhus C

Denmark

E-mail: ppedersen@econ.au.dk 


\section{Introduction}

It is well known that unemployment creates a multitude of economic and social problems from loss of production in the aggregate to economic hardship and social problems for individuals and families. Focus in the present paper is on a specific potential outcome from unemployment shocks. There is a clear risk that a jump up in unemployment, among other consequences, could induce retirement earlier than initially planned for individuals. This would result in costs for the public sector as most exits from the labor force are to programs fully or partially financed by the state. In a more long run perspective an unemployment induced decline in the average age of retirement could have an impact also on attitudes or expectations regarding the age at which retirement from the labor force is considered appropriate. This in turn could make it even more politically difficult to adjust pension programs to the demographic prospects in most OECD countries.

Accelerated exit from the labor force will be reflected in the labor force participation rate for older workers. The counterpart of a decline in effective participation is a number of different outcomes, i.e. long term unemployment before entry to a retirement program - at or before the official retirement age - entry to disability pension or to a non-health related early retirement program, or it could finally be an exit to become provided for by other family members, typically a spouse.

It is thus necessary to consider the possibility of "communicating vessels" as part of the outcome of a reduced employment potential for older workers, i.e. an initial increase in unemployment could subsequently appear as increases in disability pension, long term sickness benefits or entry to mostly absorbing states of non-health related early retirement programs. Independently of the specific pathway a potential consequence of a cyclical downturn is thus a more long run decline in production capacity along with a deterioration of the public sector budget.

In the following, Section 2 contains a brief survey of results in the fairly few studies with focus on retirement induced by individual unemployment. Section 3 summarizes first some main characteristics of early retirement programs in Denmark. Next, Section 3 contains an overview of trends in the most recent 30 years in labor force participation rates among older workers along with a new calculation of the average age at retirement over the same period, conditional on retirement occurring from a state in the labor force ${ }^{1}$. After presenting these more aggregate trends, Section 4

\footnotetext{
1 Alternative estimates of the average retirement age have included transitions to national Old Age Pension for individuals not being in the labor force. Relative to the calculations and estimates presented here, including these transitions create an upward bias in the average retirement age,
} 
moves on to a more disaggregate approach describing exits to a number of different programs with emphasis on age, eligibility rules and unemployment, both aggregate and for relevant age groups.

Section 5 presents results from a number of estimations of the probability of entering retirement based on micro panel data for the years 1981 - 2009 where individual unemployment is entered as explanatory variable along with other relevant background factors. Finally, Section 6 concludes the study.

\section{Literature survey: recent evidence regarding induced retirement due to unemployment}

The number of studies with specific focus on the eventual impact from individual unemployment on the retirement decision seems to be fairly limited. Lack of sufficient micro panel samples is one possible explanation. Another is related to challenges regarding concepts and measurement, i.e. when does retirement occur? One could choose the criterion that retirement is dated to the time of entry to a formal retirement program, either social security based or consisting of entry to a private or labor market pension scheme. The challenge here is that effective retirement in relation to the labor force in many situations occur before this event. This could for instance be a lay off followed by long term unemployment, by long term sickness benefits or by entry to disability pension, in all cases followed by entry after some time to an absorbing state of full retirement. A further complication is that the probability that an individual lay off for an older worker after some time will be followed by retirement may interact positively with the average national unemployment rate, i.e. a given level of individual unemployment among older workers is expected to have a bigger impact on retirement the higher is the aggregate unemployment.

The dominant finding in the literature is - not surprisingly - that increasing individual unemployment among older workers increases the probability of retirement from the labor force. There are exceptions, however, as Chan and Stevens (1999, 2001) in studies of the impact from job loss among men in the USA find that this leads to labor force participation at higher ages due to loss of health insurance and eligibility to medicare in case of premature exit from the labor force.

In a survey using German labor market data Radl (2007) finds the dominant result, i.e. duration of unemployment among older workers increases the probability of retirement. In Kim (2009) focus is on labor force participation among 55-64 years old women and men in 9 OECD countries over the years 1984 - 2001. Kim (2009) divides the sample into different types of welfare states using the classification from Esping-Andersen (1990). Pooled time series-cross section analyses are done for the three types of welfare states where labor force participation rates are explained by three classes 
of variables, i.e. social welfare expenditures, a number of economic variables including aggregate unemployment and a number of demographic variables. In the present context Kim (2009) finds that aggregate unemployment has a significant negative effect on labor force participation among the 55 - 64 years old in the liberal type welfare states. In the conservative type welfare states, the result is quite the opposite, labor force participation is increasing with unemployment, while finally the impact is insignificant in the social democratic welfare states.

Tatsiramos (2010) uses data from the European Community Household Panel (ECHP) to analyse how job displacement among older workers influences the transition probabilities to early retirement relative to re-employment. The analysis has explicit emphasis on the impact from crosscountry differences in the institutional environment. A main result is that programs with “communicating vessels" properties, along with loss of human capital during long term unemployment significantly increases the probability of job displacement resulting in early retirement. In countries with fairly generous unemployment insurance programs, including extended maximum benefit duration rules for older workers, Tatsiramos (2010) finds that unemployment with higher probability is a pathway to early retirement than to re-employment.

Hairault et al. (2010) focus on the eventual importance for the employment rate of older workers of the distance to the lowest age for entry into retirement programs. They find a clear tendency for countries with a low first eligibility age to have low employment rates for workers up to 5 years younger than this age. This effect is interpreted in a job search context as an interaction between unemployment insurance generosity and depressed demand for older workers resulting jointly in low employment rates in the age group up to the first eligibility for social security.

Coile and Levine (2011) use U.S. CPS and Census data for the years 1980 - 2009 for men 55 - 59 years old and data for a number of years since 2000 for 70 - 79 years old men. The purpose is to study the impact from recessions on the probability of retiring starting from age 62 being the youngest age for beginning to collect social security benefits. For the older age group the purpose is to study whether income in the 70 s is affected by the labor market situation at the time of retirement. Coile and Levine (2011) find that a recession around the age where retirement is possible has a positive impact on the retirement decision and a negative impact on social security income later in life. The effects are most pronounced for individuals with fairly little education working in insecure jobs.

Duval et al. (2011) analyse the relationship between labor force participation rates and recessions in 30 OECD countries for the years 1960 - 2008. Their main finding is a significant negative and long 
lasting impact from severe recessions while moderate recessions result in a smaller, temporary impact on labor force participation rates ${ }^{2}$. Not surprisingly, they find the strongest impact for the 60 - 64 years old, and in the cross-country perspective, the strongest impact is found where retirement programs have incentives that reinforce the influence from a recession.

The hypothesis of a competing risks setting, a "communicating vessels" property between unemployment and Disability Pension is the topic in Riphahn (1997) who, working with German data rejects the hypothesis of substitution. The same conclusion is found in Bingley et al. (2011) for Denmark, cf. below. On the other hand, Autor and Duggan (2003) using U.S. data for the years 1984 - 2001, Karlström et al. (2008) using data from a natural experiment in Sweden for the 60 64 years old group and Bratsberg et al. (2010) working with Norwegian data all find strong substitution. In the Norwegian case, especially for men.

For older workers it is well known that unemployment insurance benefits can function as a substitution for retirement, and in a longer run turn out to be a pathway to early or normal retirement. This could reflect a market determined decline in re-employment probabilities and/or specific rules in unemployment insurance for groups of older workers. Heyma and van Ours (2005) for instance found that the abolition of active search requirement for unemployed 57,5 to 65 years old Dutch workers had a strong negative impact on re-employment probabilities. Kyyrä and Wilks (2007) found for Finland that the increase from age 53 to 55 before becoming eligible for “unemployment insurance pension” resulted in a very big increase in re-employment probabilities for the 53 - 54 years old. Unemployment, among other pathways to early retirement in Denmark, is analyzed in Larsen and Pedersen (2008). Schils (2008) finds in a competing risks model analyzed with data from Germany, the Netherlands and UK that unemployment only seems to have a significant positive impact on the transition to early retirement relative to employment in the UK.

Focus in Cremer et al. (2009) is on the setting up of a theoretical model encompassing the different ways in which unemployment insurance can function (or malfunction) as a pathway to early retirement. Finally, Bloemen et al. (2011) is an interesting continuation of the analyses in Heyma and van Ours (2005). Bloemen et al. (2011) analyse the return in 2004 to requiring active job search from unemployed workers older than 57,5 years in the Netherlands. They find a significant increase in re-employment probabilities, but find at the same time higher transition rates to sickness and to Social Disability Pension (SDP).

\footnotetext{
${ }^{2}$ For Denmark Duval et al. (2011) identify only one severe recession occurring in 1986.
} 


\section{Retirement programs, retirement age and unemployment - the Danish experience since} 1980

As a background for the analyses in the subsequent sections, we present a brief survey of the Danish Social Security retirement programs. Until 1979 National Old Age Pension (OAP) and social disability pension (SDP) were the only elements in the Social Security part of provision for retirement, along with unemployment or sickness benefits as a pathway to retirement. Until 2004 people became eligible for OAP from age 67. From 2004 the age was reduced to $65^{3}$. Unemployment insurance is not available after reaching the OAP age. SDP is granted on health or on a mixture of health and social criteria between ages 18 and 64 (66). SDP benefits are means tested against income from work with a fairly high ceiling before benefits are fully phased out and depends also on whether the recipient is single or not.

In 1979 a new program, the so-called Post Employment Wage (PEW), was introduced. PEW is an early retirement program with eligibility based solely on being at least 60 years old and having sufficient tenure as member of an unemployment insurance fund ${ }^{4}$. Entry to the program became much higher than forecasted. In subsequent years a number of rules have been implemented to reduce entry to the program. From 1999 it has been possible to combine working with a proportional reduction in PEW benefits.

Besides the PEW program, a more restricted early retirement program in the Social Security area, called the Transitional Benefits Program (TBP), was opened for long term unemployed people 50 54 years old in 1992. In 1994 eligibility was extended to 55 - 59 years old long term unemployed people $^{5}$. Entry was closed again in 1996. Benefits were set at 80 per cent of PEW benefits and those admitted to the program remained in it and were transferred to the PEW program by the age 60 .

Two other policy changes are relevant in the present context. Maximum duration of unemployment insurance benefits was extended for 55 - 59 years old workers in the years 1994 - 2006. For workers 50 - 54 years old, maximum benefit duration was extended in the years 1994 - 1998, in both cases until the age 60 reaching eligibility to PEW. Finally, 58 - 59 years old unemployed

\footnotetext{
${ }^{3}$ This policy change is somewhat surprising in relation to demographic trends and policy changes in other countries. An obvious interpretation is that the majority of the 65 and 66 years old were collecting Post Employment Wage (PEW) or SDP benefits, both of which are significantly higher that OAP.

${ }^{4}$ Unemployment insurance is not mandatory in Denmark. Membership of so-called Ghent type unemployment insurance funds is voluntary. The funds are administered by unions with revenues from membership fees and with the state as the actor carrying the residual financial burden under recessions.

${ }^{5}$ Eligibility was conditional on having been unemployed for 12 out of the most recent 15 months and on being member of an unemployment insurance fund.
} 
workers were exempt until 2007 from the obligation to enter active labor market policy measures as a condition for continued benefit eligibility.

Next, this section presents a brief survey of some recent trends in labor force participation rates and unemployment among older workers in Denmark along with the aggregate trend in the average age at retirement from the labor force. First, Figure 1 demonstrates a point mentioned above, i.e. that unemployment and disability pension are not substitutes over the 40 years since the mid-1960s. Instead, disability pension appears as a program running on its own tracks independently of the cyclical movements in the Danish economy ${ }^{6}$.

Figure 1. Aggregate unemployment rate and participation rate in Disability Pension, 1966 - 2007.

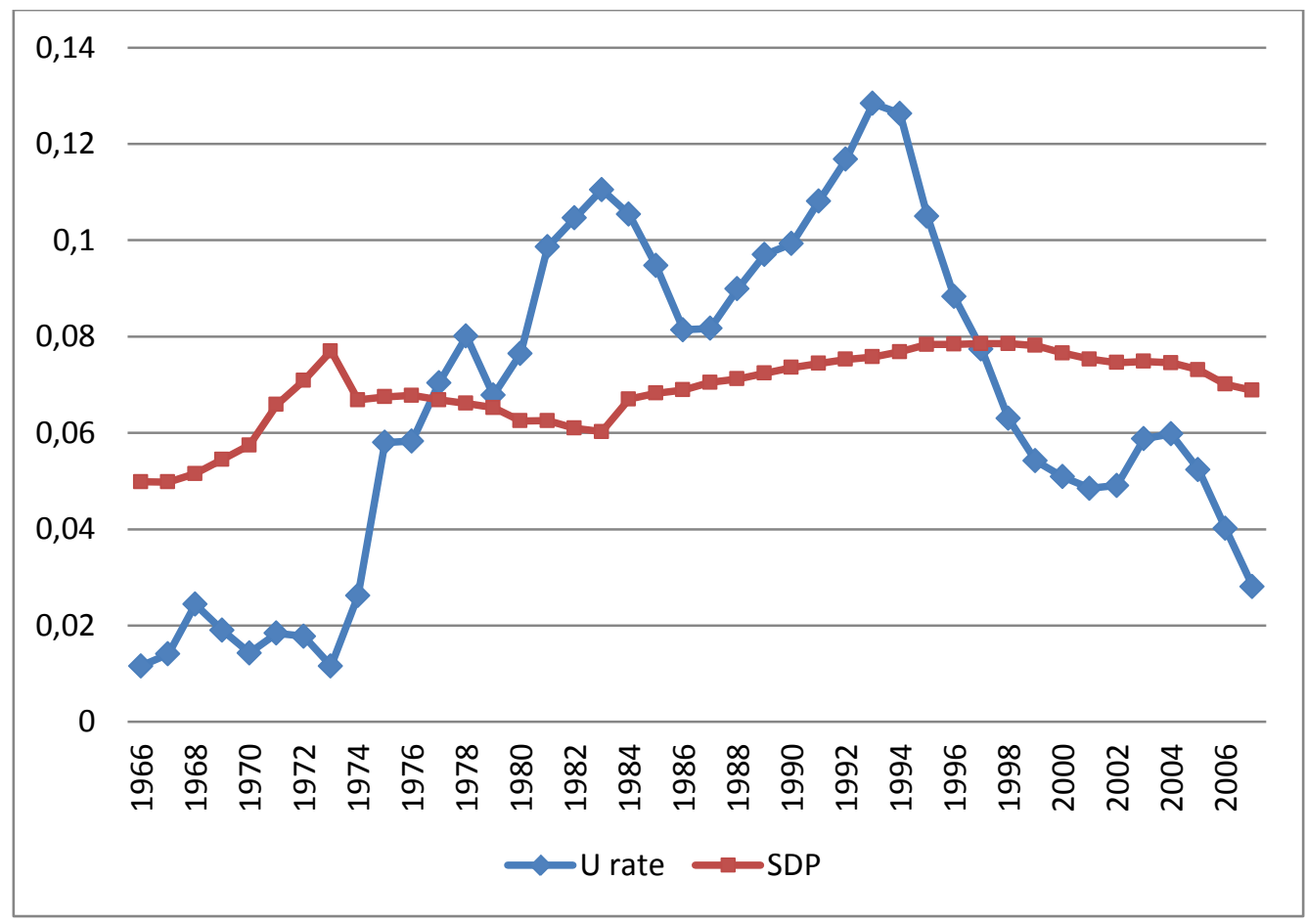

The following two graphs, Figures 2 and 3 show labor force participation rates since 1981 for the most relevant age groups regarding early retirement, the 55 - 59 and the 60 - 64 years old, separately for men and women. For men, 55 - 59 years old, a declining trend is found until the quite strong decline occurring when the TBP program was introduced in 1992. After the closing of this program in 1996 the labor force participation rate returns to a somewhat higher level. Finally, the

\footnotetext{
${ }^{6}$ A detailed description of reforms and smaller program changes in SDP over the period covered in Figure 1 can be found in Bingley et al. (2011).
} 
financial crisis from 2008 is followed by a fairly strong decline of about 5 percentage points, overall resulting in a decline of nearly 10 percentage points for the 55 - 59 years old men over the 30 years since 1981. The 60 - 64 years old follows a quite different pattern showing a U profile with a minimum around the turn of the century. Overall, most of the decline in labor force participation over the first 20 years is recovered during the most recent 10 years.

Figure 2. Labor force participation rate, men, 55-59 and 60-64, 1981-2010

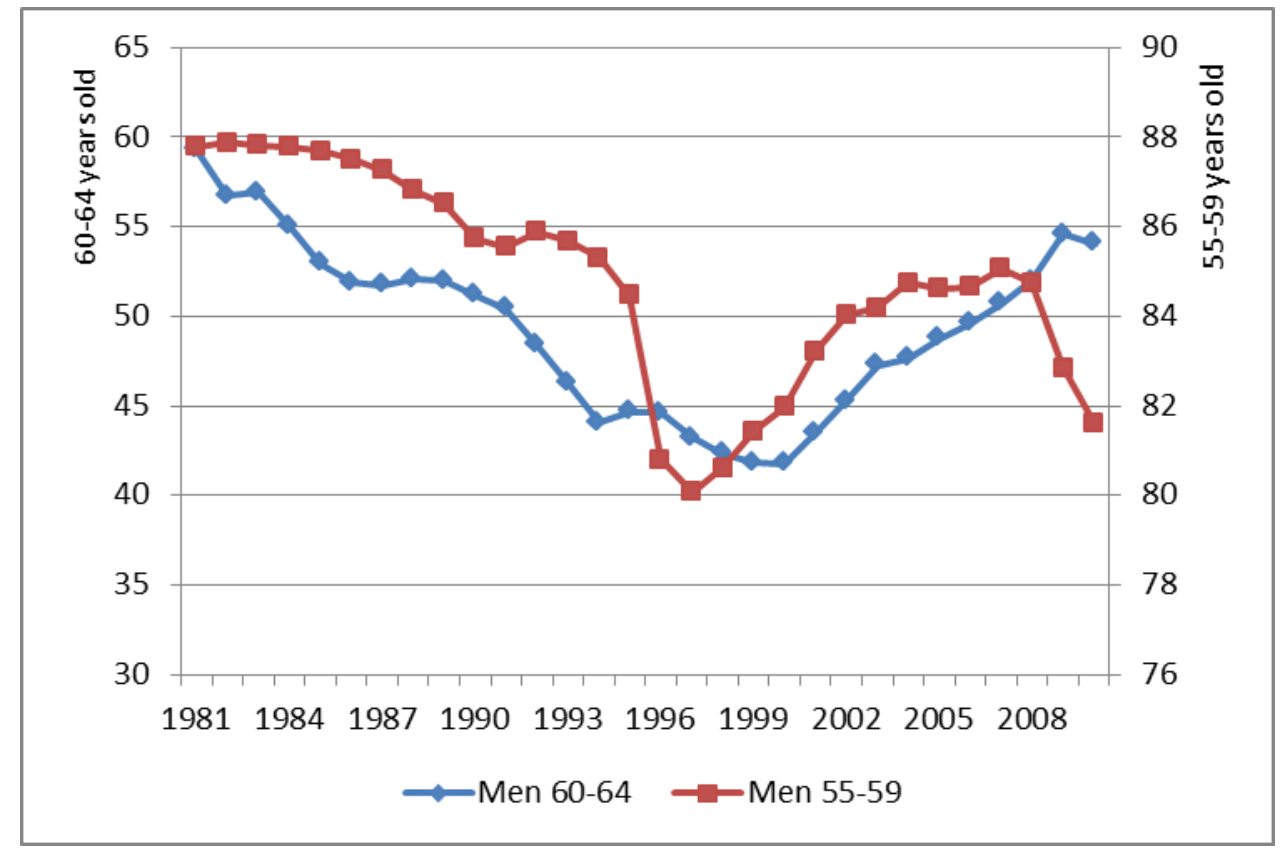

The situation is quite different for women as shown in Figure 3. For the 55 - 59 years old, strong cohort effects result in an increasing trend, with an overall increase of 25 percentage points. The only break in this trend is the initial 10 percentage points reaction to the TBP program. For the 60 64 years old, the profile follows the same $U$ form as found for men, but an increase of 20 percentage points in the most recent 10 years more than neutralizes the 10 percentage points decline found over the first 20 years. We notice that the cyclical impact from the financial crisis is more moderate than for men. The most probable explanation is the segregation by gender in the Danish labor market. Only few women are employed in building and construction and in the cyclically most sensitive sectors of manufacturing industry where employment went down most strongly in the initial phase of the financial crisis. 
Figure 3. Labor force participation rate, women, 55-59 and 60-64, 1981-2010

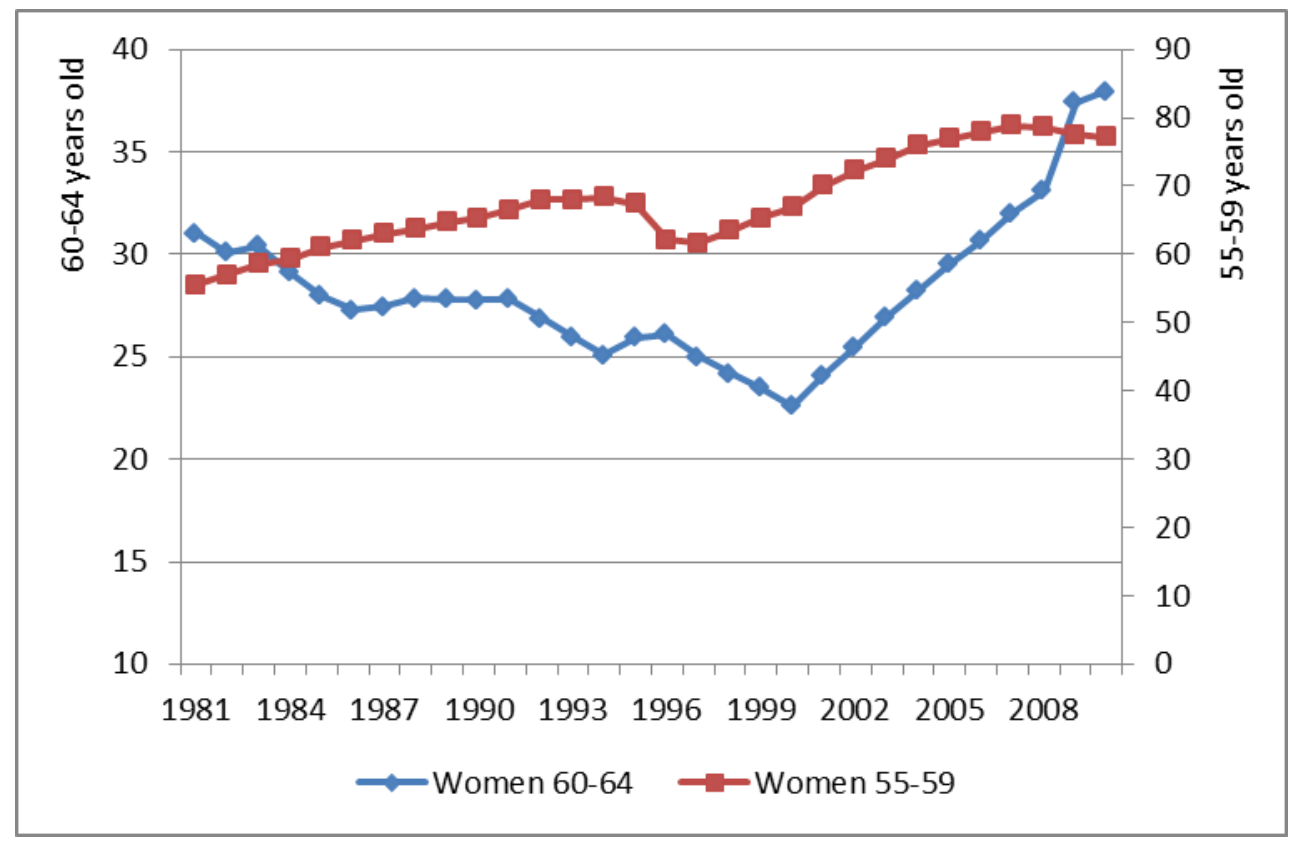

Next, Figure 4 shows labor force participation rates by gender from age 65. Unemployment insurance is not available for this age group so labor force participation means income from work or independent business above a classification threshold set by Statistics Denmark. For men, we observe a steep declining trend until the turn of the century followed by stabilization around 15 per cent. For women, the profile is a - very - flat U resulting in 2010 in a return to about the initial level of 6 per cent in 1981.

There is no obvious close relationship between the labor force participation for men shown in Figure 3 and the unemployment rates shown in Figure 5. Overall, the unemployment rates follow an inverted $U$ profile, but the maximum occurs well before the minimum found for the labor force participation rates. 
Figure 4. Labor force participation rate after official retirement age, 1981-2010 .

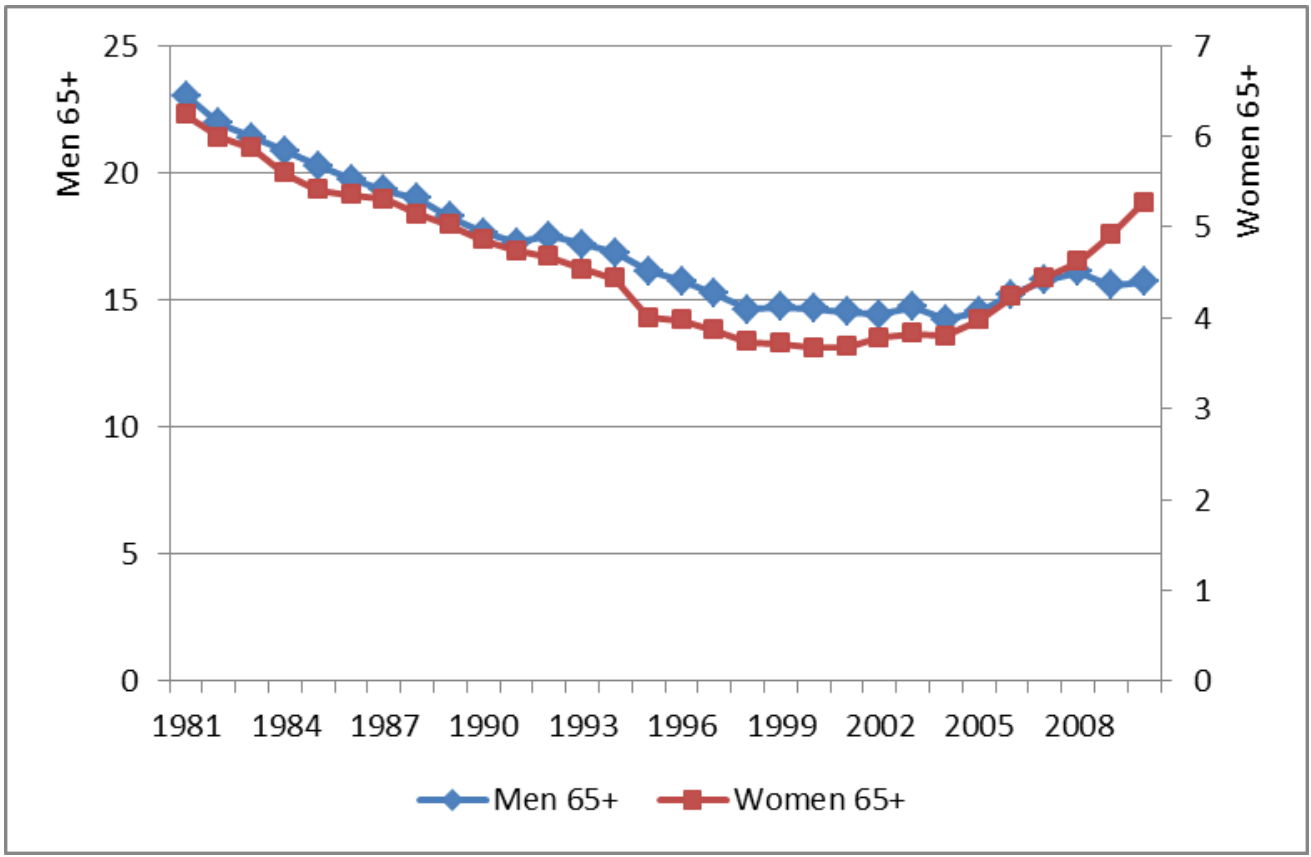

Figure 5. Unemployment rates, men, 50-54, 55-59 and 60-64, 1980 - 2010.

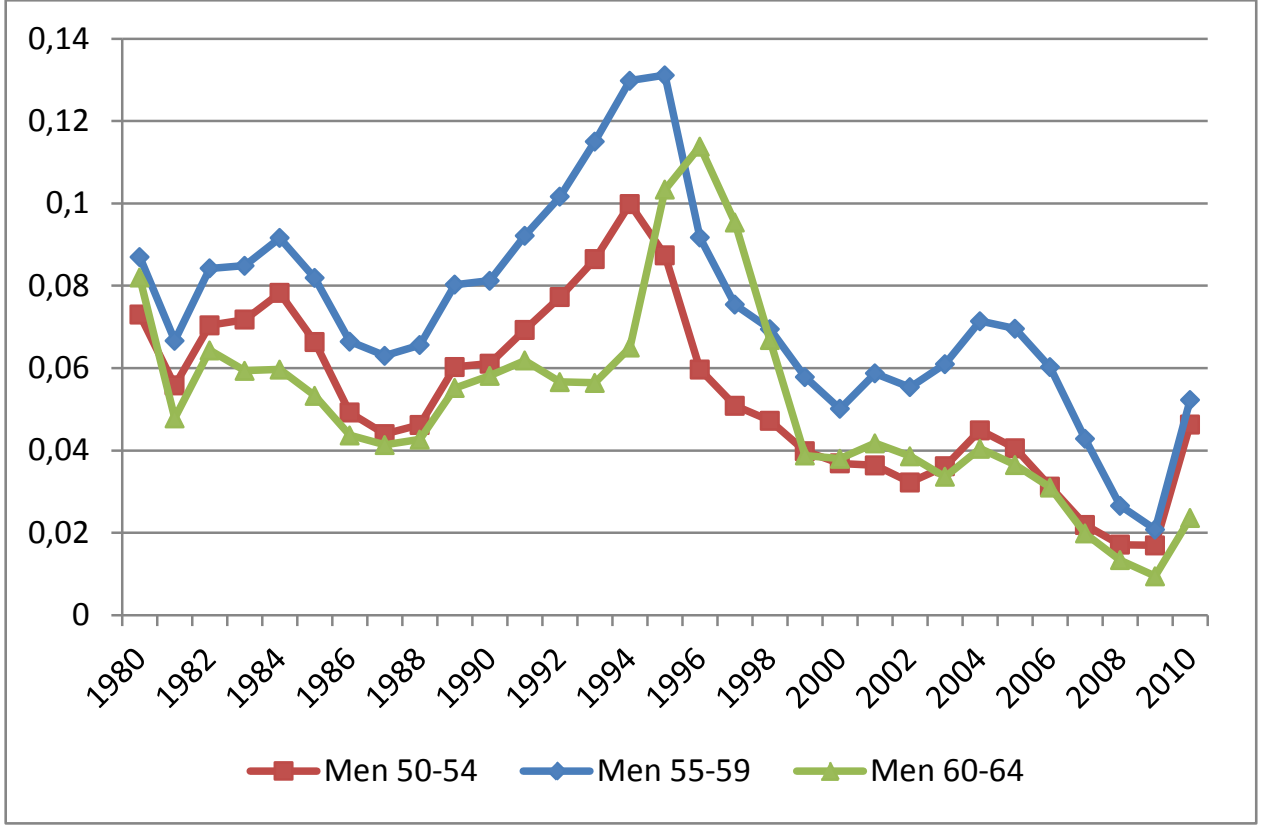

${ }^{7}$ This was 67 until 2004 and after that 65 years for both women and men. 
Finally, we show in Figure 6 the average age at entry to a retirement program conditional on the individual having been present in the labor force in the year prior to retirement. Figure 6 shows a clear expected reaction to the introduction in 1979 of the PEW program. Average age at entry declines with about a year, both for women and men. The other very clear impact is found from the TBP program resulting in a temporary decline of about 2 years in the average age. In the most recent years, the average age trends upwards with about a year. Overall, this highly aggregate age profile shows no clear sensitivity to the very big cyclical changes over the period, cf. the very big variation in aggregate unemployment shown in Figure 1.

Figure 6. Average age at entry to a retirement program conditional on labor force participation in the year prior to entry, $1980-2008$.

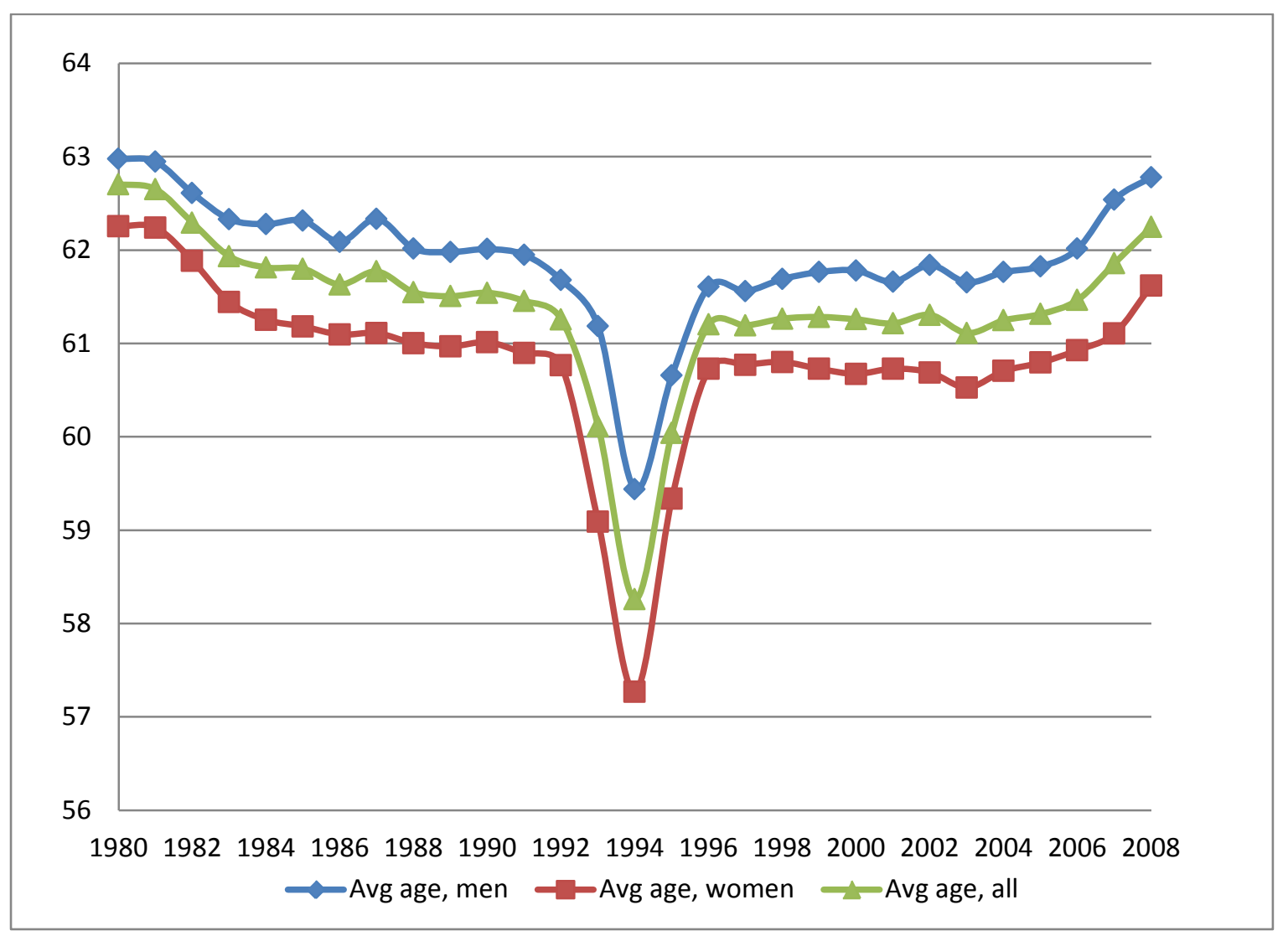




\section{Exit trends by age, gender and programs}

In this section we present a brief survey of the transition rates to retirement by age groups, gender and by programs. First, Figures 7 and 8 show exit rates to retirement for three different age groups in their 50s. The significantly higher level for the 58 - 59 years old reflects eligibility to PEW from age 60. This is captured in the figure as exits to retirement are categorized relative to the last year the individual is in the labor force. For the two younger age groups the impact from the temporary TBP program is clearly visible.

Figure 7. Exit rates to retirement by age groups, men, 1981 - 2008.

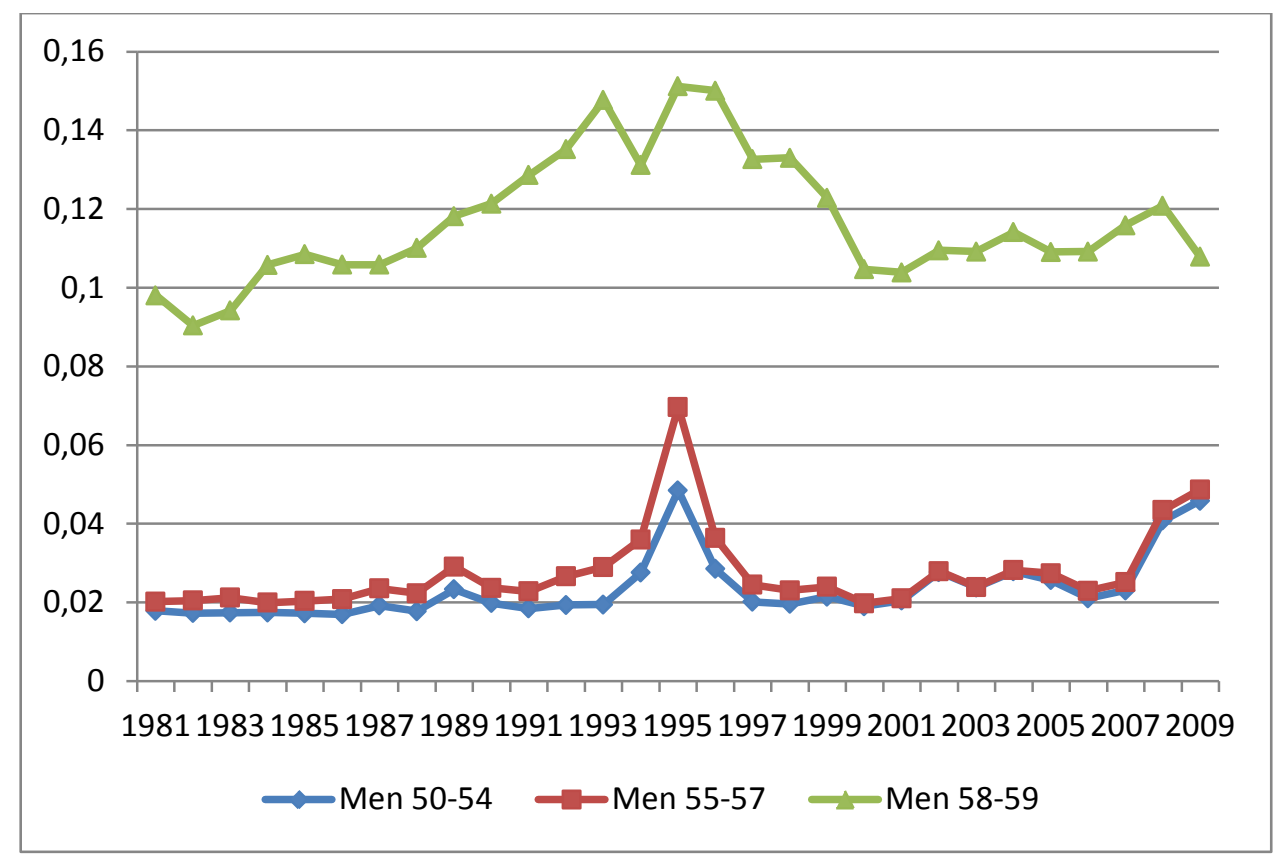


Figure 8. Exit rates to retirement by age groups, women, $1981-2008$.

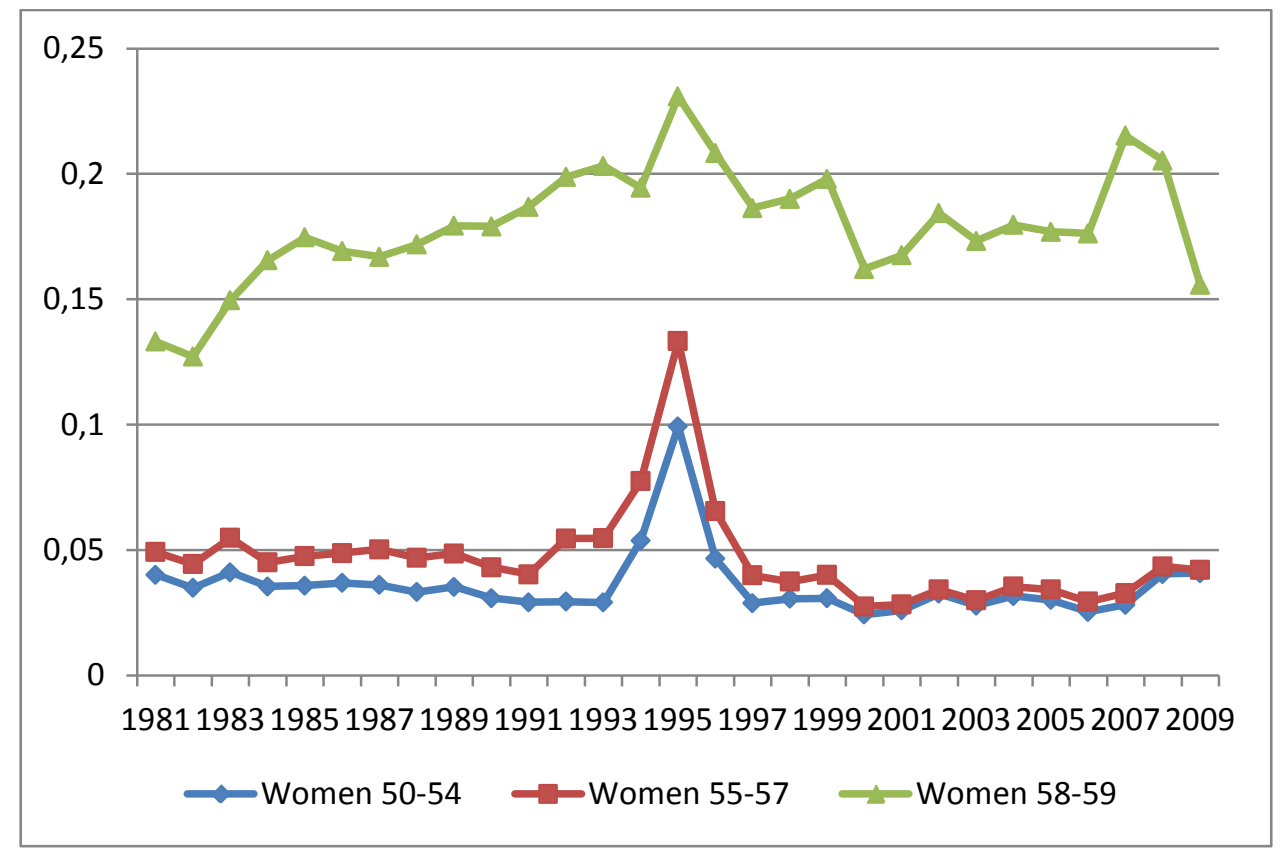

Figure 9 shows the exit rates by gender for $60-62$ and $63-64$ years old. Exit rates are higher for women and are slightly higher for the youngest age groups. The transition rates became stationary and or slightly declining from the turn of the century for both women and men. To avoid cohort effects, we summarize in Figures 10 and 11 the exit rates by program for men 55 - 59, respectively 60 - 64 years old. Exit rates are shown to SDP, PEW and a residual group called “Other Pension”. The different scales used in the graphs implies that the volatility in the exit rates is smaller for the 55 - 59 years old than for the 60 - 64 years old group. For men 55-59 years old a substitution seems to take place in the years with the financial crisis with a jump up in the exit rate to "Other Pension" and a corresponding decline in the exit rate to PEW. For men 60-64 years old we also find a decline in the exit rate to PEW, here however in the years just before the onset of the financial crisis. For transitions to “Other Pension” we find the same quite strong increase as for the 55-59 years old. 
Figure 9. Exit rates to retirement by age groups, women and men, 1981 - 2008.

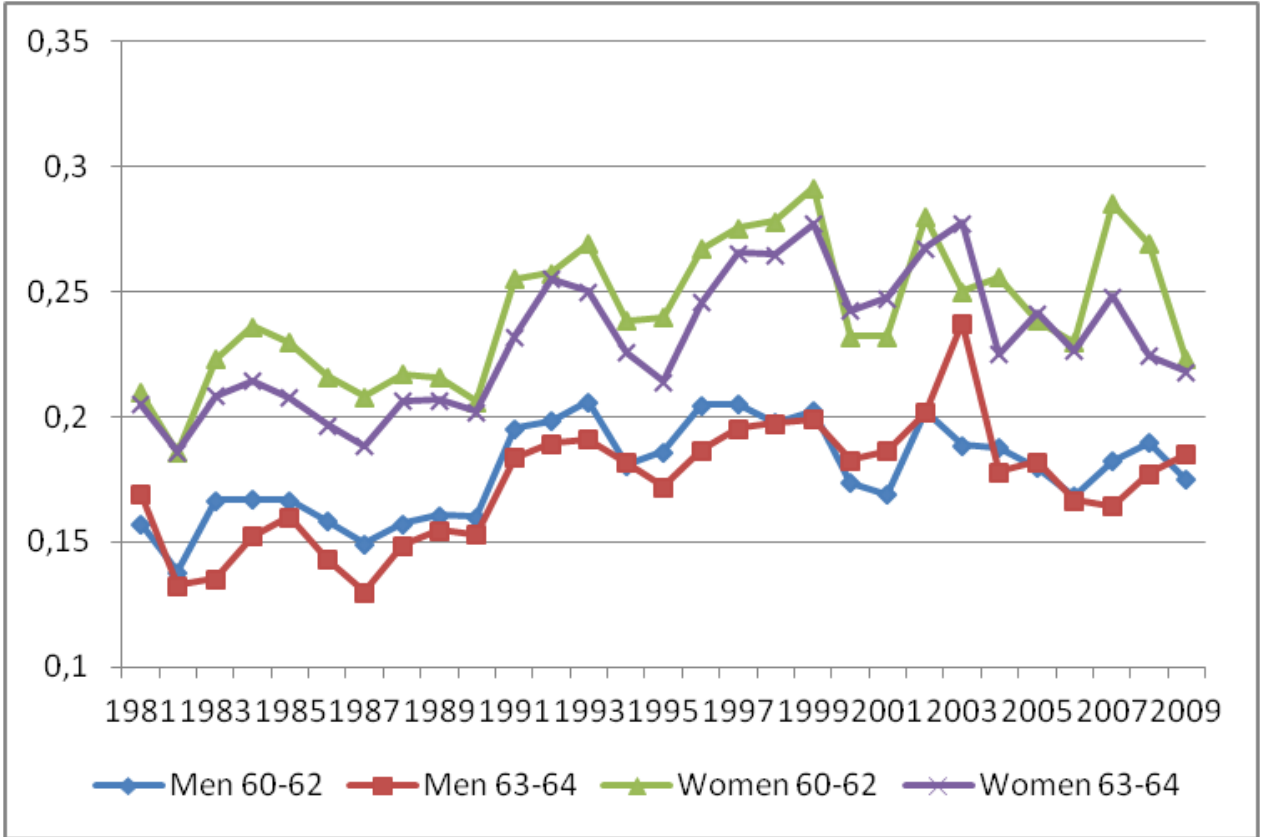

Figure 10. Exit rates by program, men, 55-59 years old, 1981 - 2008

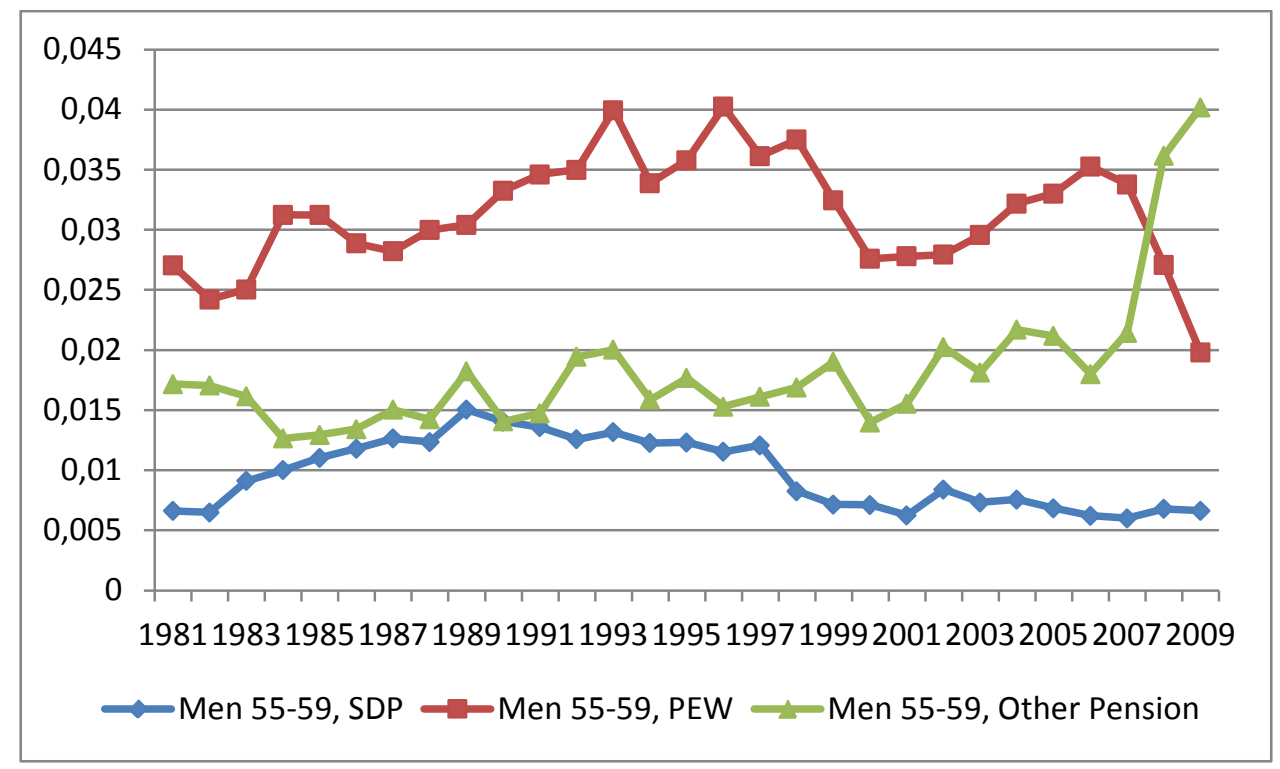


Figure 11. Exit rates by program, men, 60-64 years old, 1981 - 2008

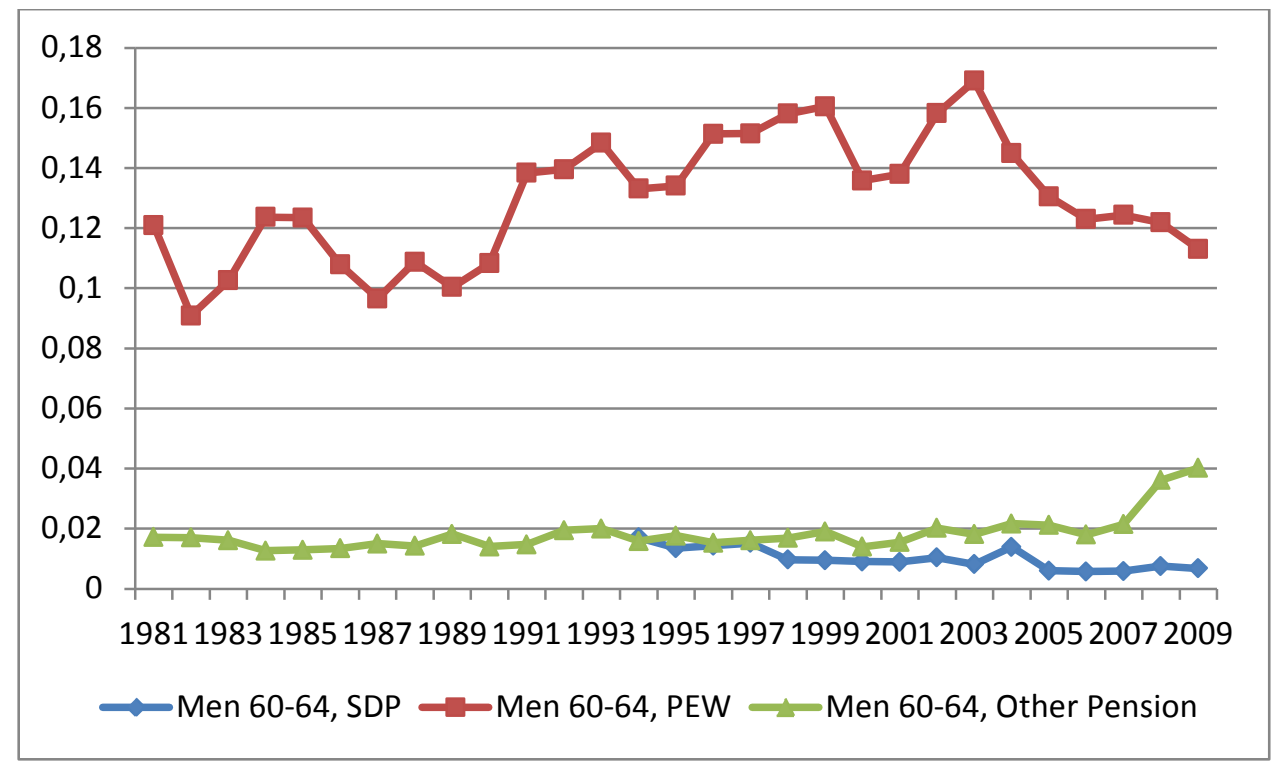

\section{Impact from individual unemployment - estimation results}

In this section we present the results from a number of regressions with the common purpose of measuring the impact from individual unemployment on the retirement decision. Data are based on administrative registers in Statistics Denmark and are available for the period 1980 to 2009. The data set contains all individuals present in the country in each specific year and consists of a broad set of demographic, economic and labor market variables measured annually.

In the two sets of estimations presented below retirement is defined as a transition from one year to the next from being in the labor force to be in one of five specific retirement programs, OAP, SDP, PEW, TBP and the residual category “Other Pension”. First, we present results from running probit estimations on making the transition to retirement against staying in the labor force for a number of selected years. We include a number of demographic variables along with age for all 45-65 years old in the labor force. Further, we include individual annual unemployment in the two years prior to the eventual transition to retirement.

Next, we present results using the same left hand side variable, but running the estimations on four different age groups, 50-54 years old, 55-59 years old, 60-65 years old and finally 60-63 years old. The same explanatory variables are included as above and furthermore year dummies are included for the period 1985-2009. 
In Table 1 we show the marginal effects on the retirement probability from a number of variables for individuals in the labor force in 1985, for all and separately for women and men estimated on all individuals 45-65 years old. The same type of results are presented in Tables 2-5 for the years 1990/1991, 1995/1996, 2000/2001 and 2005/2006. Together, this represents a collection of years with quite different cyclical situations. In Table 1, the impact from the educational variables - with compulsory school only as the excluded group - is negative as expected, most so for those with a long theoretical education. We find the same profiles for men and women regarding the marginal effect from the educational variables. For women, the difference between having only compulsory school and having post-school education is bigger than for men. Being married or cohabiting reduces the retirement probability, more for men than for women. In the probit estimation for all, we find a significantly lower retirement probability from being a man. Finally, individual unemployment significantly increases the probability of retirement. We find the same, although smaller in absolute terms, when we look at the marginal effects from lagged individual unemployment. Looking upon the marginal effect from individual unemployment across the included periods, the two first periods differ with marginal effects around 5 per cent while the impact is between 9 and 10 per cent in the three last periods. This difference in profiles seems unrelated to the underlying macroeconomic situation. Overall, the contribution from individual unemployment dominates the impact from the other explanatory variables.

Table 1. Marginal effects in probit estimations of the transition to retirement. Age dummies included.

\begin{tabular}{|c|c|c|c|c|c|c|}
\hline & \multicolumn{6}{|c|}{ 1985/1986 } \\
\hline & \multicolumn{2}{|c|}{ All } & \multicolumn{2}{|c|}{ Men } & \multicolumn{2}{|c|}{ Women } \\
\hline & $\mathrm{dF} / \mathrm{dx}$ & $\mathrm{z}$ & $\mathrm{dF} / \mathrm{dx}$ & $\mathrm{z}$ & $\mathrm{dF} / \mathrm{dx}$ & $\mathrm{Z}$ \\
\hline Vocational & -0.0092 & -21.66 & -0.0038 & -8.22 & -0.0168 & -21.23 \\
\hline Short & -0.0138 & -11.57 & -0.0087 & -6.29 & -0.0202 & -9.49 \\
\hline Medium & -0.0142 & -21.21 & -0.0084 & -10.53 & -0.0214 & -18.37 \\
\hline Long & -0.0241 & -25.89 & -0.0173 & -20.30 & -0.0334 & -13.62 \\
\hline Couple & -0.0114 & -24.21 & -0.0146 & -24.78 & -0.0082 & -10.23 \\
\hline Male & -0.0193 & -47.83 & - & - & - & - \\
\hline $\mathrm{U}_{\mathrm{t}-1}$ & 0.0249 & 21.84 & 0.0264 & 21.39 & 0.0181 & 8.47 \\
\hline $\mathrm{U}_{\mathrm{t}}$ & 0.0469 & 43.23 & 0.0418 & 34.36 & 0.0537 & 27.51 \\
\hline Pseudo $\mathrm{R}^{2}$ & 0.1798 & & 0.2043 & & 0.1540 & \\
\hline
\end{tabular}


Table 2. Marginal effects in probit estimations of the transition to retirement. Age dummies included.

\begin{tabular}{|c|c|c|c|c|c|c|}
\hline & \multicolumn{6}{|c|}{ 1990/1991 } \\
\hline & \multicolumn{2}{|c|}{ All } & \multicolumn{2}{|c|}{ Men } & \multicolumn{2}{|c|}{ Women } \\
\hline & $\mathrm{dF} / \mathrm{dx}$ & $\mathrm{Z}$ & $\mathrm{dF} / \mathrm{dx}$ & $\mathrm{Z}$ & $\mathrm{dF} / \mathrm{dx}$ & $\mathrm{z}$ \\
\hline Vocational & -0.0062 & -15.51 & -0.0026 & -5.34 & -0.0109 & -16.05 \\
\hline Short & -0.0129 & -12.54 & -0.0083 & -6.38 & -0.0179 & -10.70 \\
\hline Medium & -0.0111 & -18.25 & -0.0080 & -10.48 & -0.0146 & -14.85 \\
\hline Long & -0.0205 & -24.64 & -0.0168 & -19.91 & -0.0237 & -12.09 \\
\hline Couple & -0.0134 & -29.39 & -0.0163 & -27.16 & -0.0098 & -13.63 \\
\hline Male & -0.0112 & -29.34 & - & - & - & - \\
\hline $\mathrm{U}_{\mathrm{t}-1}$ & 0.0262 & 25.24 & 0.0259 & 20.15 & 0.0263 & 15.61 \\
\hline $\mathrm{U}_{\mathrm{t}}$ & 0.0501 & 53.08 & 0.0480 & 41.11 & 0.0519 & 33.70 \\
\hline Pseudo $\mathrm{R}^{2}$ & 0.2156 & & 0.2268 & & 0.2045 & \\
\hline
\end{tabular}

Table 3. Marginal effects in probit estimations of the transition to retirement. Age dummies included.

\begin{tabular}{|c|c|c|c|c|c|c|}
\hline & \multicolumn{6}{|c|}{ 1995/1996 } \\
\hline & \multicolumn{2}{|c|}{ All } & \multicolumn{2}{|c|}{ Men } & \multicolumn{2}{|c|}{ Women } \\
\hline & $\mathrm{dF} / \mathrm{dx}$ & $\mathrm{z}$ & $\mathrm{dF} / \mathrm{dx}$ & $\mathrm{z}$ & $\mathrm{dF} / \mathrm{dx}$ & $\mathrm{Z}$ \\
\hline Vocational & -0.0076 & -19.52 & -0.0034 & -7.13 & -0.0127 & -19.75 \\
\hline Short & -0.0132 & -14.86 & -0.0070 & -6.09 & -0.0202 & -14.12 \\
\hline Medium & -0.0144 & -26.50 & -0.0123 & -17.61 & -0.0163 & -18.60 \\
\hline Long & -0.0224 & -29.26 & -0.0181 & -22.05 & -0.0283 & -17.94 \\
\hline Couple & -0.0095 & -22.41 & -0.0133 & -23.99 & -0.0063 & -9.30 \\
\hline Male & -0.0133 & -35.83 & - & - & - & - \\
\hline $\mathrm{U}_{\mathrm{t}-1}$ & 0.0239 & 26.84 & 0.0227 & 20.10 & 0.0265 & 18.53 \\
\hline $\mathrm{U}_{\mathrm{t}}$ & 0.0949 & 113.72 & 0.0765 & 71.11 & 0.1166 & 88.37 \\
\hline Pseudo $\mathrm{R}^{2}$ & 0.2517 & & 0.2495 & & 0.2521 & \\
\hline
\end{tabular}


Table 4. Marginal effects in probit estimations of the transition to retirement. Age dummies included.

\begin{tabular}{|c|c|c|c|c|c|c|}
\hline & \multicolumn{6}{|c|}{$2000 / 2001$} \\
\hline & \multicolumn{2}{|c|}{ All } & \multicolumn{2}{|c|}{ Men } & \multicolumn{2}{|c|}{ Women } \\
\hline & $\mathrm{dF} / \mathrm{dx}$ & $\mathrm{Z}$ & $\mathrm{dF} / \mathrm{dx}$ & $\mathrm{Z}$ & $\mathrm{dF} / \mathrm{dx}$ & $\mathrm{z}$ \\
\hline Vocational & -0.0071 & -21.56 & -0.0047 & -10.90 & -0.0099 & -19.50 \\
\hline Short & -0.0094 & -13.95 & -0.0063 & -6.88 & -0.0124 & -12.28 \\
\hline Medium & -0.0113 & -27.27 & -0.0092 & -15.96 & -0.0131 & -21.46 \\
\hline Long & -0.0173 & -30.96 & -0.0159 & -23.88 & -0.0182 & -17.77 \\
\hline Couple & -0.0094 & -27.02 & -0.0134 & -27.90 & -0.0044 & -8.65 \\
\hline Male & -0.0080 & -26.49 & - & - & - & - \\
\hline $\mathrm{U}_{\mathrm{t}-1}$ & 0.0074 & 7.73 & 0.0121 & 9.50 & 0.0016 & 1.08 \\
\hline $\mathrm{U}_{\mathrm{t}}$ & 0.0911 & 116.07 & 0.0826 & 79.14 & 0.1008 & 84.24 \\
\hline Pseudo $\mathrm{R}^{2}$ & 0.2376 & & 0.2232 & & 0.2556 & \\
\hline
\end{tabular}

Table 5. Marginal effects in probit estimations of the transition to retirement. Age dummies included.

\begin{tabular}{|c|c|c|c|c|c|c|}
\hline & \multicolumn{6}{|c|}{$2005 / 2006$} \\
\hline & \multicolumn{2}{|c|}{ All } & \multicolumn{2}{|c|}{ Men } & \multicolumn{2}{|c|}{ Women } \\
\hline & $\mathrm{dF} / \mathrm{dx}$ & $\mathrm{Z}$ & $\mathrm{dF} / \mathrm{dx}$ & $\mathrm{Z}$ & $\mathrm{dF} / \mathrm{dx}$ & $\mathrm{Z}$ \\
\hline Vocational & -0.0098 & -23.71 & -0.0061 & -11.19 & -0.0142 & -22.37 \\
\hline Short & -0.0151 & -20.01 & -0.0119 & -11.66 & -0.0184 & -16.02 \\
\hline Medium & -0.0158 & -32.14 & -0.0139 & -19.33 & -0.0180 & -24.82 \\
\hline Long & -0.0241 & -38.81 & -0.0208 & -27.00 & -0.0279 & -26.35 \\
\hline Couple & -0.0062 & -15.17 & -0.0112 & -19.84 & -0.0001 & -0.20 \\
\hline Male & -0.0127 & -34.18 & - & - & - & - \\
\hline $\mathrm{U}_{\mathrm{t}-1}$ & 0.0143 & 11.33 & 0.0167 & 10.33 & 0.0110 & 5.50 \\
\hline $\mathrm{U}_{\mathrm{t}}$ & 0.0998 & 88.58 & 0.0947 & 64.84 & 0.1060 & 60.04 \\
\hline Pseudo $\mathrm{R}^{2}$ & 0.2318 & & 0.2173 & & 0.2489 & \\
\hline
\end{tabular}

For reasons of space, we illustrate the marginal effects from the age dummies in Figure 12, including only three years 1985, 1995 and 2005, and including only ages 50 - 58 as the marginal effects from age dummies for higher ages are at the same level throughout. The main finding is the impact from the TBP program which was open in 1995 for people 50-59 years old conditional on being long-term unemployed. Another finding is the very low marginal effects for age younger than 60 in 2005, compared also with 1985. A possible interpretation is that this reflects two special policy measures which were in effect in 2005, cf. Section 3 For unemployed 55-59 years old the maximum duration of unemployment benefits was suspended. Further, the obligation to enter activation programs as a condition for continued eligibility for unemployment benefits was 
cancelled for 58-59 years old people. Both these temporary policy measures are expected to make it more attractive to postpone retirement.

Figure 12. Marginal effects from age dummies, 50-58 years old in 1985, 1995 and 2005.

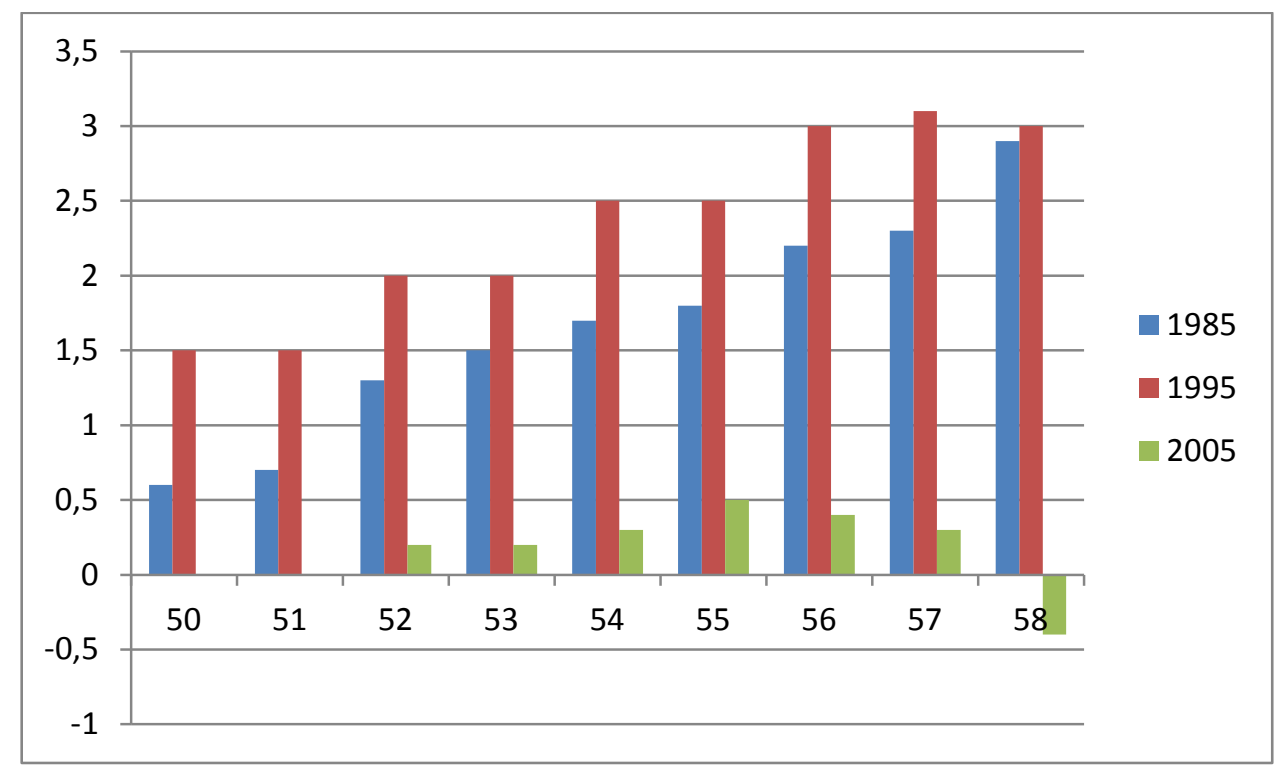

Results from the second set of estimations are shown in Tables $6-9$. Looking first at the marginal effects from educational levels very small differences are found for the 50-54 years old, while education is related to increasingly bigger differences in retirement probabilities by increasing age. This is most pronounced for individuals with a long education while only small, non-systematic differences are found in the marginal effects from having a short or a medium long education. The marginal effects from gender is the same as above, i.e. for all age groups we find a negative marginal effect for men. Regarding marital status, the marginal effect is negative both for women and men 50-54 years old. For those 55-59 years old the marginal effect is still negative for men but becomes insignificant for women. Finally being married or cohabiting is found to have a positive marginal effect on the retirement probability for people 60-63/65 years old. For the variable in focus in the present context, annual individual unemployment, the marginal effect is positive on the retirement probability across Tables 6 - 9. The effect is much stronger from the most recent unemployment experience, except for the 60-65 years old. The marginal impact from individual unemployment is increasing with age, i.e. from 0.064 for the 50-54 years old to 0.144 for the 55-59 years old. For the 60-65 years old the result in table 8 is relevant for the period where OAP began at 67 with a marginal contribution from unemployment at 0.165 . Table 8, finally, reports results for 
the short period in which OAP began at 65. The marginal impact from unemployment is here 0.308. The estimation period is however quite short. Dominantly, the marginal effect from unemployment is stronger for women. Compared to the other explanatory variables, individual unemployment is very important explaining differences in the retirement probability.

Table 6. Marginal effects in probit estimations of the transition to retirement. (Year dummies included, 1981-2009).

\begin{tabular}{|l|l|l|l|l|l|l|}
\hline & \multicolumn{9}{c|}{$50-54$ years } \\
\hline & \multicolumn{2}{|c|}{ All } & \multicolumn{2}{c|}{ Men } & \multicolumn{2}{c|}{ Women } \\
\hline & $\mathrm{dF} / \mathrm{dx}$ & $\mathrm{z}$ & $\mathrm{dF} / \mathrm{dx}$ & $\mathrm{z}$ & $\mathrm{dF} / \mathrm{dx}$ & $\mathrm{z}$ \\
\hline Vocational & -0.0087 & -75.93 & -0.0059 & -41.82 & -0.0115 & -61.39 \\
\hline Short & -0.0099 & -42.25 & -0.0070 & -24.67 & -0.0128 & -32.71 \\
\hline Medium & -0.0124 & -83.63 & -0.0083 & -42.15 & -0.0159 & -68.36 \\
\hline Long & -0.0126 & -58.95 & -0.0094 & -40.17 & -0.0160 & -38.97 \\
\hline Couple & -0.0124 & -98.76 & -0.0160 & -100.31 & -0.0079 & -39.60 \\
\hline Male & -0.0070 & -65.58 & - & - & - & - \\
\hline $\mathrm{U}_{\mathrm{t}-1}$ & 0.0096 & 33.75 & 0.0118 & 34.24 & 0.0068 & 14.67 \\
\hline $\mathrm{U}_{\mathrm{t}}$ & 0.0661 & 261.13 & 0.0525 & 168.34 & 0.0807 & 196.68 \\
\hline Pseudo $\mathrm{R}^{2}$ & 0.1156 & & 0.1226 & & 0.1085 & \\
\hline
\end{tabular}

Table 7. Marginal effects in probit estimations of the transition to retirement. (Year dummies included, 1981-2009).

\begin{tabular}{|l|l|l|l|l|l|l|}
\hline & \multicolumn{9}{|c|}{55 -59 years } \\
\hline & \multicolumn{2}{|c|}{ All } & \multicolumn{2}{c|}{ Men } & \multicolumn{2}{c|}{ Women } \\
\hline & $\mathrm{dF} / \mathrm{dx}$ & $\mathrm{z}$ & $\mathrm{dF} / \mathrm{dx}$ & $\mathrm{z}$ & $\mathrm{dF} / \mathrm{dx}$ & $\mathrm{z}$ \\
\hline Vocational & -0.0178 & -80.10 & -0.0114 & -42.05 & -0.0255 & -69.05 \\
\hline Short & -0.0278 & -55.34 & -0.0201 & -32.65 & -0.0369 & -43.81 \\
\hline Medium & -0.0280 & -92.07 & -0.0226 & -57.14 & -0.0347 & -71.17 \\
\hline Long & -0.0437 & -96.73 & -0.0342 & -70.78 & -0.0570 & -62.24 \\
\hline Couple & -0.0066 & -27.88 & -0.0140 & -46.02 & 0.0023 & 5.93 \\
\hline Male & -0.0224 & -108.57 & - & - & - & - \\
\hline $\mathrm{U}_{\mathrm{t}-1}$ & 0.0220 & 38.25 & 0.0252 & 35.44 & 0.0181 & 19.11 \\
\hline $\mathrm{U}_{\mathrm{t}}$ & 0.1441 & 286.19 & 0.1226 & 195.42 & 0.1706 & 207.59 \\
\hline Pseudo $\mathrm{R}^{2}$ & 0.0862 & & 0.0841 & & 0.0785 & \\
\hline
\end{tabular}


Table 8. Marginal effects in probit estimations of the transition to retirement. (Year dummies included).

\begin{tabular}{|l|l|l|l|l|l|l|}
\hline & \multicolumn{9}{|c|}{$60-65$ years, $1985-2006$} \\
\hline & \multicolumn{2}{|c|}{ All } & \multicolumn{2}{c|}{ Men } & \multicolumn{2}{c|}{ Women } \\
\hline & $\mathrm{dF} / \mathrm{dx}$ & $\mathrm{z}$ & $\mathrm{dF} / \mathrm{dx}$ & $\mathrm{z}$ & $\mathrm{dF} / \mathrm{dx}$ & $\mathrm{z}$ \\
\hline Vocational & 0.0058 & 8.94 & 0.0149 & 19.37 & -0.0132 & -11.40 \\
\hline Short & -0.0296 & -17.57 & -0.0121 & -5.68 & -0.0559 & -19.96 \\
\hline Medium & -0.0099 & -10.41 & -0.0223 & -19.04 & 0.0082 & 5.04 \\
\hline Long & -0.0985 & -80.86 & -0.0883 & -68.72 & -0.1154 & -39.31 \\
\hline Couple & 0.0038 & 5.67 & 0.0027 & 3.08 & 0.0067 & 6.31 \\
\hline Male & -0.0517 & -85.67 & - & - & - & - \\
\hline $\mathrm{U}_{\mathrm{t}-1}$ & 0.1472 & 66.01 & 0.1324 & 48.47 & 0.1731 & 45.45 \\
\hline $\mathrm{U}_{\mathrm{t}}$ & 0.1647 & 84.04 & 0.1727 & 71.67 & 0.1560 & 46.78 \\
\hline Pseudo $\mathrm{R}^{2}$ & 0.0420 & & 0.0399 & & 0.0341 & \\
\hline
\end{tabular}

Table 9. Marginal effects in probit estimations of the transition to retirement. (Year dummies included).

\begin{tabular}{|c|c|c|c|c|c|c|}
\hline & \multicolumn{6}{|c|}{$60-63$ years, $2004-2009$} \\
\hline & \multicolumn{2}{|c|}{ All } & \multicolumn{2}{|c|}{ Men } & \multicolumn{2}{|c|}{ Women } \\
\hline & $\mathrm{dF} / \mathrm{dx}$ & $\mathrm{Z}$ & $\mathrm{dF} / \mathrm{dx}$ & $\mathrm{Z}$ & $\mathrm{dF} / \mathrm{dx}$ & $\mathrm{Z}$ \\
\hline Vocational & -0.0072 & -6.79 & 0.0018 & 1.35 & -0.0209 & -11.71 \\
\hline Short & -0.0384 & -18.65 & -0.0290 & -11.50 & -0.0511 & -14.53 \\
\hline Medium & -0.0227 & -17.04 & -0.0300 & -17.69 & -0.0134 & -6.23 \\
\hline Long & -0.1040 & -62.88 & -0.0911 & -48.05 & -0.1237 & -39.03 \\
\hline Couple & 0.0244 & 24.12 & 0.0062 & 4.64 & 0.0475 & 30.02 \\
\hline Male & -0.0543 & -59.15 & - & - & - & - \\
\hline $\mathrm{U}_{\mathrm{t}-1}$ & 0.0758 & 17.12 & 0.0789 & 14.96 & 0.0733 & 9.37 \\
\hline $\mathrm{U}_{\mathrm{t}}$ & 0.3099 & 73.42 & 0.2962 & 59.89 & 0.3243 & 42.56 \\
\hline Pseudo $\mathrm{R}^{2}$ & 0.0339 & & 0.0329 & & 0.0273 & \\
\hline
\end{tabular}

Figure 13 summarizes the marginal effects from year dummies for the 50-54 and the 55-59 years old. For the 50-54 years old the highest marginal effect is found for 1994-1996 when TBP was open for this age group and again, somewhat surprisingly, in the years after the turn of the century. For the 55-59 years old the TBP program was open 1992-1996 corresponding to the biggest marginal effects found for these years. Also for this group we find higher values after 2000.

The increase in the marginal effect from year dummies after the turn of the century most probably reflects that nobody in the 55-59 years old group are in the TBP program from 2001 on and that the youngest in the 50-54 years old group that entered TBP in the last year the program was open in 1996 left the program in 2006. The profile in the marginal effects from the year dummies 
consequently seems to reflect a selection phenomenon, i.e. a return to a more "normal" situation for people 50-59 years old. Finally, the marginal effects in 2008 and 2009 are at the same level as in the “peak” TBP year 1995, most probably reflecting the impact from the financial crisis. However, even for these years, the year dummy contribution is small relative to the contribution from individual unemployment rates.

Figure 13. Marginal effects to year dummies, 1986 - 2009, 50-54 and 55 - 59 years old.

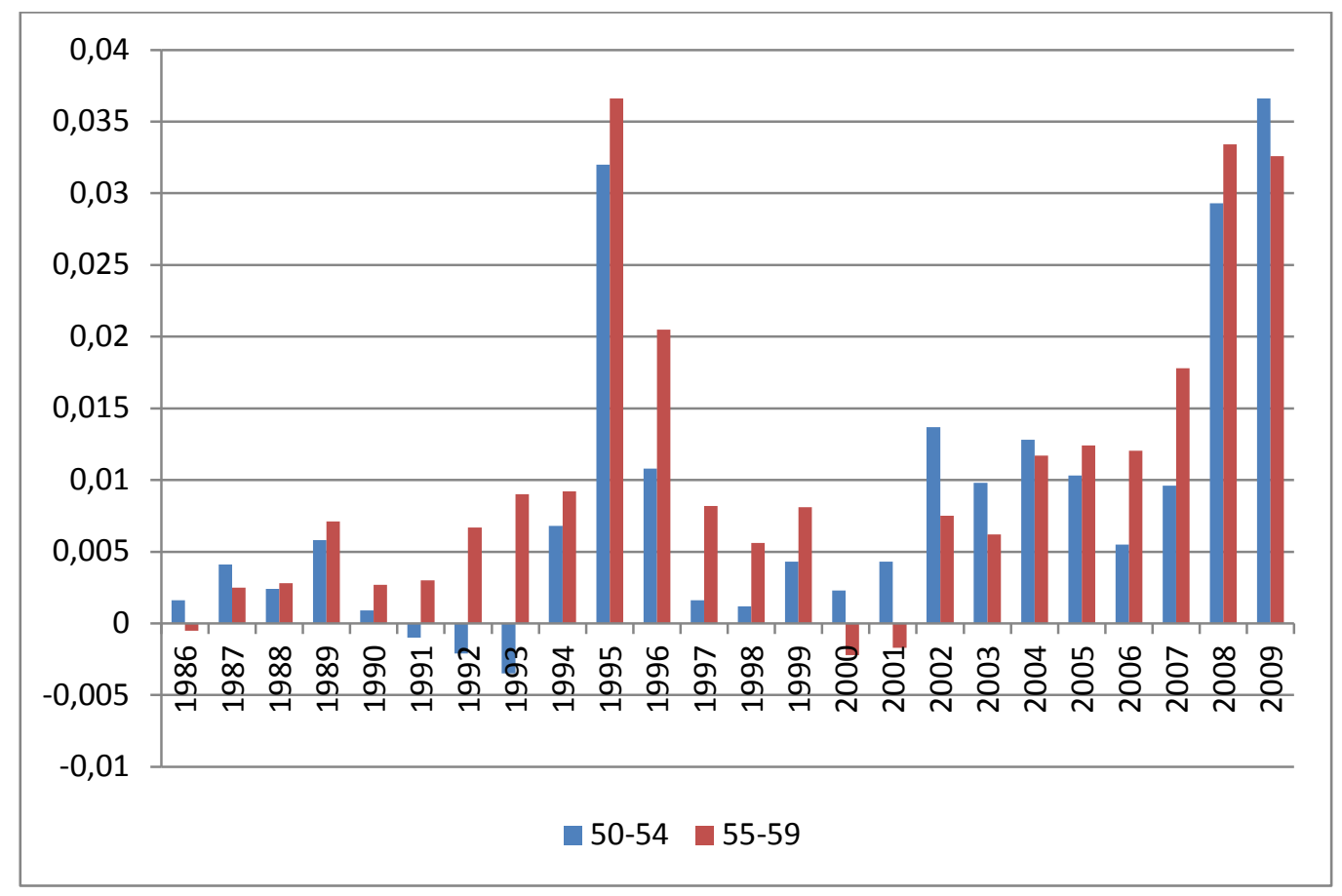

\section{Conclusions and summary}

The motivation in the present study is to examine the eventual relationship between individual unemployment and labor force participation. This is of special relevance in the contemporary setting with pension reforms made necessary by demographic prospects. A survey of the fairly few contributions in the literature concludes that the impact from an increase in individual unemployment mostly leads to an increase in the probability of entering retirement. An important point in the survey is, however, that cyclical factors interact with the policy setting and the specific institutions regarding the relationship between individual unemployment and transitions to retirement. 
A brief survey of retirement programs in Denmark with emphasis on reforms and changes was followed by a summary of the trend in labor force participation by gender for the two most relevant age groups, the 55-59 years old and those 60-64 years old. The most clear change was found for men 55-59 years old where labor force participation over the last 30 years declined with 10 percentage points.

The aggregate average age at exit from the labor force is found to be a reflection of program innovations and reforms. The interaction with the cyclical situation seems to be fairly complex as program changes with big impact on retirement behaviour appear to be endogenous relative to the state of the labor market. For the most recent years we find a somewhat surprising increase in the average retirement age.

Exit rates by age and gender show a higher level throughout for women. We find no clear trends in these exit rates and no clear relationship with the aggregate cyclical state of the economy.

The impact on retirement from individual unemployment is studied using micro panel data for the whole population covering a quarter of a century. Transition probabilities are estimated using standard demographic variables along with individual unemployment as explanatory variables. Age and year dummies reflect strong effects from program changes and from the cyclical situation in the most recent years. A main result here is a big impact on transitions to retirement from policy reforms opening new exit routes from the labor force, with timing of the reforms reflecting cyclical changes. We find throughout a significant impact from individual unemployment, increasing the probability of retirement, most strongly for women. The impact is not only significant but also big in quantitative terms relative to the impact both from demographic and educational variables and from year dummies. As expected, the impact is increasing with age.

\section{Literature}

Autor, D.H. and H.G. Duggan. 2003. The Rise in the Disability Rolls and the Decline in Unemployment. Quarterly Journal of Economics, 118(1), 157-205.

Bingley, P., N. Datta Gupta and P.J. Pedersen. 2011. Disability programs, health and retirement in Denmark since 1960. NBER Working Paper 17138.

Bloemen, H., S. Hochguertel and M. Lammers. 2011. Job search requirements for older unemployed: Transitions to employment, early retirement and disability benefits. Tinbergen Institute Discussion Papers 11-008/3

Bratsberg, B., E. Fevang and K. Røed. 2010. Disability in the Welfare State: An Unemployment Problem in Disguise? IZA Discussion Paper No. 4897.

Chan, S. and A.H. Stevens. 1999. Employment and retirement following a late-career job loss. American Economic Review 89(2), 211-216. 
Chan, S. and A.H. Stevens. 2001. Job loss and employment patterns of older workers. Journal of Labor Economics 19(2), 484-521.

Coile, C. C. and P.B. Levine. 2011. Recessions, Retirement and Social Security. American Economic Review: Papers \& Proceedings, 101:3, 23-28.

Cremer, H., J-M Lozachmeur and P. Pestieau. 2009. Use and misuse of unemployment benefits for early retirement. European Journal of Political Economy, 25(2), 174-185.

Dorn, D. and A. Sousa-Poza. 2010. "Voluntary” and "involuntary” early retirement: an international analysis. Applied Economics, 42(4), $427-438$.

Duval, R., M. Eris and D. Furceri. 2011. The Effects of Downturns on Labour Force Participation. Evidence and Causes. OECD Economics Departmernt Working Papers No. 875.

Hairault, J.-O., F. Langot and T. Sopraseuth. 2010. Distance to retirement and older workers' employment: The case foer delaying the retirement age. Journal of the European Economic Association, 8(5), 1034-1076.

Hetschko, C., A. Knabe and R. Schöb. 2011. Changing Identity: Retiring from Unemployment. CESifo WP No. 3540.

Heyma, A. and J.C. van Ours. 2005. How eligibility criteria and entitlement characteristics of unemployment benefits affect job finding rates of elderly workers. Mimeo.

Karlström, A., M. Palme and I. Svensson. 2008. The employment effect of stricter rules for eligibility to DI: Evidence from a natural experiment in Sweden. Journal of Public Economics, 92, 2071 - 2082.

Kim, J. 2009. Early retirement in the three types of welfare states. Research on Ageing, 31(5), 520-548.

Kyrrä, T., R.A. Wilke. 2007. Reduction in the long-term unemployment of the elderly: a success story from Finland. Journal of the European Economic Association 5(1), 154-182.

Larsen, M. and P.J. Pedersen. 2008. Pathways to early retirement in Denmark, 1984-2000. International Journal of Manpower, 29(5), 384-409.

Oorschot, W. van and P.H. Jensen. 2009. Early retirement differences between Denmark and the Netherlands. A crossnational comparison of push and pull factors in two small European welfare states. Journal of Aging Studies, 23, 267-278.

Radl, J. 2007. Individuelle Determinanten des Renteneintrittsalters. Statistiches Bundesamt, Wirtschaft und Statistik, 5, 511-520.

Riphahn, R. 1997. Disability retirement unemployment - substitute pathways for labor exit? An empirical test for Germany. Applied Economics 29, 531-561.

Schils, T. 2008. Early Retirement in Germany, the Netherlands, and the United Kingdom: A Longitudinal Analysis of Individual Factors and Institutional Regimes. European Sociological Review, 24(3), 315-329.

Tatsiramos, K. 2010. Job displacement and the transitions to re-employment and early retirement for non-employed older workers. European Economic Review, 54(4), 517-535. 